\title{
TO Clicando - inclusão social e digital de idosos
}

\author{
Kátia Vanessa Pinto de Meneses ${ }^{a}$, Patrícia Azevedo Garcia ${ }^{b}$, Carolina Becker Bueno Abreu \\ Grasielle Tavares Paulin ${ }^{a}$
}

${ }^{a}$ Departamento de Terapia Ocupacional, Universidade de Brasília - UnB, Brasília, DF, Brasil.

${ }^{b}$ Departamento de Fisioterapia, Universidade de Brasília - UnB, Brasília, DF, Brasil.

\begin{abstract}
Resumo: Introdução: A implementação de estratégias de inclusão digital e de atividades sociais, físicas, cognitivas e de lazer repercutem positivamente na preservação das capacidades físico-cognitivas e na qualidade de vida dos idosos. Objetivo: Relatar a experiência de implantação e desenvolvimento do projeto de extensão universitária “TO Clicando", descrevendo suas características, seus objetivos e suas contribuições acadêmicas e comunitárias. Método: O “TO Clicando" foi criado em 2011, visando a promover a inclusão social e digital de idosos, por meio de oficinas de informática, estimulação cognitiva, atividades manuais e atividades de socialização. As atividades foram desenvolvidas em uma instituição de longa permanência. Os idosos foram avaliados semestralmente. As oficinas e avaliações foram realizadas por alunos do curso de terapia ocupacional da Universidade de Brasília, orientados por professores dos cursos de fisioterapia e de terapia ocupacional. Resultados: Um total de 254 idosos participou das 11 turmas de oficinas de informática, oito turmas de estimulação cognitiva e cinco turmas de atividades manuais, e de duas confraternizações. O projeto contou com a participação de professores, alunos bolsistas e voluntários, e possibilitou o desenvolvimento de projeto de pesquisa e apresentações em congressos. A adesão e as produções sugerem que as atividades atendem ao interesse dos idosos, trazem novas perspectivas de participação social e abrem campo para práticas e pesquisas. Conclusão: O "TO Clicando" é um exemplo viável de projeto de extensão que envolve a participação de docentes, discentes e da comunidade, configurando espaço de aprendizagem, socialização, inclusão social e digital do idoso, permitindo a articulação entre ensino, pesquisa e extensão universitária.
\end{abstract}

Palavras-chaves: Idoso, Socialização, Ensino, Terapia Ocupacional.

\section{OT Clicking - digital and social inclusion of the elderly}

\begin{abstract}
Introduction: The implementation of strategies of digital inclusion and physical, cognitive and social activities has a positive effect on the preservation of the physical and cognitive abilities and quality of life of the elderly. Objective: To report the experience of establishing and developing a university extension project called "OT Clicking", describing its characteristics, goals, and academic and community contributions. Method: The "OT Clicking" project was created in 2011 to promote social and digital inclusion of the elderly by means of computer workshops, cognitive stimulation workshops, hands-on activities, and socialization activities. The activities were developed in a long-term care facility. The elderly were evaluated every six months. Workshops and assessments were performed by students of the occupational therapy course at the University of Brasilia under the guidance of teachers of the physiotherapy and occupational therapy departments. Results: Two hundred and fifty four senior citizens actively attended 11 computer workshops, eight cognitive stimulation workshops, five hands-on activities, and two socialization activities. Teachers, fellow students, and volunteers participated, enabling the development of a research project and conference presentations. The project's attendance and production suggest that the activities serve the interests of the elderly, bring new perspectives of social participation, and open a field for practice and
\end{abstract}

Autor para correspondência: Kátia Vanessa Pinto de Meneses, Unidade de Ensino e Docência, Faculdade de Ceilândia, Universidade de Brasília, Centro Metropolitano, Conjunto A, Lt. 1, Ceilândia Sul, CEP 72220-900, Brasília, DF, Brasil, e-mail: katiavpmeneses@gmail.com Recebido em Abr. 13, 2015; $1^{\text {a }}$ Revisão em Dez. 18, 2015; Aceito em Fev. 28, 2016. 
research. Conclusion: "OT Clicking" is a viable example of extension project which includes teachers, students and the community, configuring a space for learning, socialization, and social and digital inclusion of the elderly, allowing connection between university teaching, research and extension.

Keywords: Aged, Socialization, Teaching, Occupational Therapy.

\section{Introdução}

O envelhecimento populacional é um fenômeno mundial e, no Brasil, o crescimento da população idosa vem ocorrendo rapidamente (VERAS, 2009). Projeçôes da população do Brasil, por sexo e idade, do Instituto Brasileiro de Geografia e Estatística apontam que a populaçáo idosa vai mais do que triplicar nas próximas quatro décadas, passando de menos de 15 milhóes em 2020 para cerca de 51 milhões em 2050 (INSTITUTO..., 2010). Nesta perspectiva, o grupo etário composto por pessoas acima de 60 anos crescerá de $6,7 \%$, em 2010, para cerca de $22 \%$ da população brasileira, em 2050 (INSTITUTO..., 2010).

Estudos demonstram que esse processo de envelhecimento pode ser acompanhado pelo declínio das capacidades físicas e cognitivas, dependendo dos hábitos de vida (FELICIANO; MORAES; FREITAS, 2004; LIMA-COSTA; BARRETO; GIATTI, 2003; GURIAN, 2002), e que atividades que proporcionam satisfação à vida - como atividades sociais, físicas, cognitivas e de lazer - auxiliam na preservação da saúde de idosos, repercutindo positivamente na qualidade de vida desses indivíduos (HSU, 2007; OLIVEIRA; GARCIA, 2011).

Santos, Foroni e Chaves (2009) identificaram o papel protetor da participação em atividades de lazer, incluindo o exercício físico, o exercício mental e a manutenção das relações sociais, nas funçôes cognitivas durante o processo de envelhecimento. Dias, Duarte e Lebrão (2010), em revisão sistemática, observaram efeitos longitudinais positivos da prática das atividades sociais, produtivas e de lazer, no envelhecimento, principalmente sobre a capacidade funcional, o estado cognitivo, o bem-estar e a mortalidade.

Adicionalmente, estudos demonstram o beneficio da inclusão digital para a população idosa (FERREIRA et al., 2008; NUNES, 2006; VECHIATO; VIDOTTI, 2010). O uso da informática permite ao idoso se manter informado e em contato com amigos e familiares, conhecer diferentes pessoas, participar de grupos sociais, favorecendo sua socialização, e possibilita novas alternativas para a realização de atividades cotidianas, como fazer compras e pesquisas pela internet (VECHIATO; VIDOTTI, 2010).

Nesse cenário, Veras (2009) ressalta que os fatos e evidências apontam a necessidade de mudanças urgentes no cuidado à populaçáo idosa, com estruturas criativas e inovadoras, e com propostas de açôes diferenciadas. Entretanto, esse autor aponta que os esforços no Brasil permanecem pontuais e desarticulados (VERAS, 2009). As iniciativas devem considerar os determinantes sociais, econômicos, comportamentais, pessoais e culturais, o ambiente físico e o acesso aos serviços, e incentivar, essencialmente, a prevenção, o cuidado e a atenção integral à saúde (VERAS, 2009).

Compreendendo-se a importância da participação em atividades sociais, produtivas e de lazer, como meio de promover saúde e independência, e proporcionar qualidade de vida aos idosos, bem como visando à inclusão digital e social de idosos, foi proposto o Projeto de Extensão Universitária "TO Clicando", da Faculdade de Ceilândia da Universidade de Brasília. Neste contexto, o objetivo deste trabalho é relatar a experiência de implantação e desenvolvimento do projeto de extensão universitária "TO Clicando", descrevendo suas características, seus objetivos e suas contribuições acadêmicas e comunitárias.

\section{Método}

\subsection{Tipo de estudo}

Trata-se de um relato de experiência de um Projeto de Extensão do curso de terapia ocupacional da Universidade de Brasília (UnB) - Campus Ceilândia.

\subsection{Coordenação e parcerias}

O Projeto de extensão universitária "TO Clicando" foi criado em fevereiro de 2011, resultado de uma parceria dos cursos de terapia ocupacional e de fisioterapia da Universidade de Brasília - Campus Ceilândia, do Programa Providência de Elevação da Renda Familiar e do Lar dos Velhinhos da Associação São Vicente de Paulo (Taguatinga-DF). O projeto foi proposto e aprovado pelo Edital do Ministério da Ciência e Tecnologia e do Conselho Nacional de Desenvolvimento Científico e Tecnológico - MCT/ CNPq, n.o 49/2010 - REID/Casa Brasil. 


\subsection{Público alvo}

O projeto de extensão é aberto à participação de idosos com idade igual ou superior a 60 anos, de ambos os sexos, residentes na comunidade ou na instituição de longa permanência "Lar dos Velhinhos".

\subsection{Local de realização do projeto}

O Projeto TO Clicando é desenvolvido no Lar dos Velhinhos, uma filial da Associação São Vicente de Paulo de Belo Horizonte, localizada em Taguatinga-DF. O Lar dos Velhinhos é uma instituição de longa permanência com capacidade para abrigar 35 idosos. A Associação São Vicente de Paulo de Belo Horizonte é uma associação civil e religiosa, sem fins lucrativos, de natureza beneficente, filantrópica e assistencial, de caráter educacional, de assistência à saúde e de assistência social, por meio da promoção da pessoa humana.

Com recursos dos parceiros do projeto, foi montada uma unidade de inclusão digital, composta por um telecentro, uma sala de convivência e uma sala de leitura. O telecentro funciona em uma sala de aproximadamente $30 \mathrm{~m}^{2}$, com dez computadores conectados a Internet em banda larga. A sala é equipada com ar condicionado, 11 mesas e 11 cadeiras. A sala de convivência, espaço de aproximadamente $50 \mathrm{~m}^{2}$, é equipada com uma mesa para dez pessoas, 20 cadeiras e um armário para guardar materiais. A sala de leitura, espaço de aproximadamente $20 \mathrm{~m}^{2}$, é equipada com estantes e diversos livros, uma mesa, cadeiras e um sofá. Todos os locais apresentam acessibilidade adequada a pessoas com deficiência, inclusive de cadeirantes.

\subsection{Objetivos do Projeto TO Clicando}

O Projeto TO Clicando tem como objetivo a inclusão social e digital de idosos, por meio de oficinas de informática, oficinas de estimulação cognitiva, oficinas de lazer e atividades manuais, palestras informativas e atividades de socializaçáo.

Também tem como objetivo integrar a UnB com a comunidade local, por meio de açôes de extensão, ensino e pesquisa, abrindo espaço para capacitação de recursos humanos para lidar com as demandas específicas da população idosa.

\subsection{Capacitação dos extensionistas}

$\mathrm{Na}$ fase de implantação do projeto TO Clicando, os alunos selecionados passaram por uma capacitação para coordenarem as oficinas, por meio de leituras de textos, organização de materiais, compreensão dos testes e sua aplicação. Neste momento, também iniciaram a busca ativa pelos idosos por meio da divulgação do projeto junto à comunidade. Foram então marcados dias para as inscriçôes e organizadas listas de espera, com a finalidade de possibilitar o acesso ao maior número de pessoas que buscaram o serviço.

\subsection{Avaliações dos participantes}

Todos os idosos foram avaliados no início e ao final da participação nas oficinas, visando (i) identificar o perfil sociodemográfico, clínico, cognitivo e físico-funcional; (ii) avaliar a qualidade de vida do público alvo do projeto, além de (iii) verificar as características de cada turma para orientação da metodologia utilizada nas oficinas. Para identificação das características sociodemográficas e clínicas, foi utilizado um formulário elaborado pelos professores do projeto, contendo nome, sexo, raça autorrelatada, data de nascimento, profissão atual, estado civil, escolaridade, comorbidades autorrelatadas, quantidade de medicamentos em uso contínuo, histórico de quedas nos últimos seis meses anteriores ao preenchimento do formulário e relato de medo de cair, e prática de exercícios físicos regulares. Para avaliação da qualidade de vida e da capacidade de realização das atividades de vida diária, foram aplicados o Health Assessment Questionaire (HAQ) e o Perfil de Saúde de Nottingham (PSN). Para rastreio cognitivo, foi aplicado o Miniexame do Estado Mental (MEEM). Para investigação de alguns aspectos do desempenho funcional, foram realizados os testes Timed $U_{p}$ and Go (TUG) e o teste de se levantar e sentar cinco vezes. Os alunos confeccionaram relatórios semanais, contendo observaçóes e análises das atividades realizadas em cada oficina, possibilitando, assim, a construção de dados subjetivos e culturais dos idosos presentes nas oficinas.

\subsection{Atividades desenvolvidas}

O Projeto TO Clicando promoveu, semestralmente, oficinas de informática, de estimulação cognitiva, de atividades manuais e atividades de socializaçáo, oferecidas gratuitamente. As oficinas foram adaptadas semestralmente de acordo com as características e necessidades dos participantes, possibilitando a participação de pessoas com diferentes limitaçóes e necessidades. Todas as atividades foram desenvolvidas por monitores, alunos extensionistas bolsistas e voluntários do curso de terapia ocupacional da UnB, supervisionados por professores dos cursos de terapia ocupacional e de fisioterapia. Os alunos 
extensionistas participaram de um minicurso semestral para capacitação sobre os instrumentos de avaliaçáo e para discutir sobre como lidar com dificuldades comuns dos idosos, além de terem participado de supervisão quinzenal.

\subsection{Oficinas de informática}

Os cursos de informática foram realizados duas vezes por semana, com duração de uma hora. Apresentavam-se os conteúdos necessários para as atividades mais populares, divididos em dois módulos, com duraçáo de cinco meses cada. No primeiro módulo, apresentaram-se os componentes do computador, o sistema operacional e as suas composiçóes, o manuseio do mouse, a utilizaçáo do teclado, o gerenciamento de pastas, a edição e a formatação de textos, e a impressão de documentos. No segundo módulo, foram apresentados os recursos da internet, a criação de e-mail e as redes sociais, e a manipulação de imagens. Como metodologia para facilitar o acompanhamento e o aprendizado, as aulas eram ministradas com, no mínimo, dois monitores para cada grupo de dez alunos, possibilitando acompanhamento individualizado, quando necessário. Utilizou-se uma apostila, criada pelos monitores, com instruçôes simples e com as sequências de açôes mais comuns e necessárias. A apostila foi cuidadosamente desenvolvida, com letras maiores do que o comum, figuras ilustrativas e espaçamento entre as linhas, facilitando a leitura e a realização das ações sem auxílio do monitor. Em cada aula, todos os idosos receberam, em papel impresso, as instruções do dia, passo a passo, e os exercícios de treinamento, tendo sido orientados a organizar o material em uma pasta. Ao final do curso, os participantes completaram uma apostila contendo todas as informaçóes e os exercícios passados durante a oficina, facilitando sua utilização e treino em casa ou em outros locais. Para turmas com idosos mais experientes, foi incluída a atividade de construção coletiva de um jornal, que possibilitou a aplicaçâo dos conhecimentos aprendidos na oficina de informática (digitação, formatação, inserção de figuras, etc.) e a interaçáo entre os participantes. Nos horários em que o telecentro não estava ocupado, os computadores foram disponibilizados aos participantes para uso da internet e para treino e aprofundamento do aprendizado.

\subsection{Oficinas de estimulação cognitiva}

As oficinas de estimulação cognitiva aconteceram uma vez por semana, com duração de duas horas, por cinco meses. A metodologia das oficinas baseou-se em aulas teóricas e práticas, com técnicas e exercícios para estimular habilidades organizacionais e cognitivas (memória, percepção, atenção, linguagem e comunicação, orientação temporal e espacial, inteligência, criatividade e resolução de problemas, funções executivas e cálculo). Primeiramente, os conteúdos foram trabalhados por meio de aulas teóricas e, em seguida, cada conteúdo foi trabalhado por meio de exercícios, jogos, atividades e dinâmicas, para potencializar as habilidades cognitivas e mentais. Os monitores acompanharam individualmente o desempenho de cada um dos participantes, auxiliando na soluçáo das dúvidas e dificuldades que surgiam. Os participantes aprenderam a identificar dificuldades, como lapsos individuais de memória e problemas de atenção, e lhes foram apresentados auxílios externos e estratégias internas. Os jogos e outros recursos dos computadores e da internet foram utilizados como auxiliares para treino da memória e para potencializar e manter as habilidades cognitivas e mentais.

\subsection{Oficinas de atividades manuais}

As oficinas de atividades manuais aconteciam uma vez por semana, com duração de uma hora. Nessas oficinas eram desenvolvidas atividades lúdicas, expressivas e manuais, de forma a favorecer a manutençáo dos aspectos físicos, mentais, cognitivos e psicossociais dos participantes. As atividades desenvolvidas nestas oficinas foram planejadas de acordo com os interesses de seus participantes. Dentre as atividades, trabalharam-se técnicas para confecção de trabalhos artesanais e promoveram-se atividades expressivas e corporais. As datas comemorativas, como Páscoa e Festa Junina, foram utilizadas para orientar os temas dos trabalhos confeccionados. Os computadores, juntamente com a internet, possibilitaram a busca de técnicas para o desenvolvimento dos trabalhos manuais, moldes, desenhos e letras de músicas e poemas. Desta forma, foi possível integrar o conhecimento aprendido nas oficinas de informática ao desenvolvimento das oficinas de lazer e atividades manuais, apresentando as facilidades e os diversos recursos disponíveis com a inclusão digital.

\subsection{Atividades de socialização}

Datas festivas foram utilizadas para promover a socialização, favorecendo a redução do isolamento e da solidão, visando a amizade e criaçáo de laços sociais. 


\section{Resultados e Discussão}

No ano de 2011, ano de implantação do Projeto TO Clicando, 254 inscriçôes foram realizadas nas diferentes oficinas oferecidas. Em relação à oficina de informática (Figura 1), foram formadas 11 turmas (cinco no primeiro semestre e seis no segundo semestre), com dez inscritos em cada turma, totalizando 110 inscritos nas oficinas de informática.

As atividades realizadas na oficina de informática contribuíram para promover o conhecimento do idoso a respeito do mundo digital e favorecer trocas entre familiares, proporcionando trocas intergeracionais. Segundo Goldfarb e Lopes (2006), estes aspectos podem facilitar e potencializar o crescimento emocional, enfraquecer os preconceitos e estimular o desejo de o idoso vivenciar uma vida plena, com diminuição da exclusão social. A análise das atividades pelo terapeuta ocupacional proporcionou graduar e oferecer complexidade nas atividades desenvolvidas, facilitando a aplicação da aprendizagem no contexto cotidiano. Observou-se, nas oficinas de informática, que o uso da tecnologia possibilitou resultados

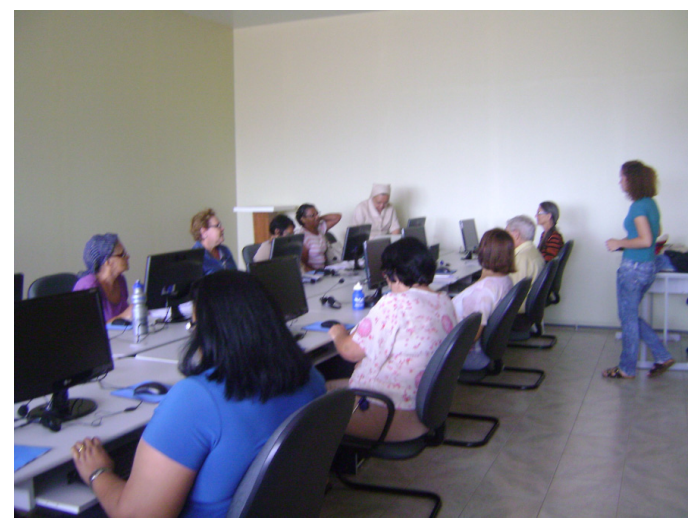

Figura 1. Oficina de Informática. que corroboram com os descritos por Raymundo (2013), como a melhora na autoestima do idoso, a segurança no ambiente doméstico, a facilidade na mobilidade, a comunicação e a oportunidade de lazer, além de oferecer ao idoso novas oportunidades e desafios, quando comparados com situaçóes e geraçôes anteriores.

Em relação às oficinas de estimulação cognitiva, (Figura 2), foram formadas oito turmas (quatro no primeiro semestre e quatro no segundo semestre), com uma média de 12 inscritos por oficina, totalizando 98 inscritos.

Por ser a memória uma das funçóes cognitivas essenciais para a vida, ela traz forte influência na autoeficácia das atividades cotidianas. Muitos idosos buscaram essa oficina com a queixa principal de problemas na memória e acabaram por descobrir dificuldades relacionadas a outras funçôes cognitivas. Foram relatadas melhoras nas relaçóes sociais e familiares, na memória, percepção e atenção, e na organização das atividades, além da aplicaçáo de estratégias apreendidas nas atividades cotidianas. A análise da atividade norteou a escolha dos jogos, dos exercícios e das dinâmicas, que contribuíram para assegurar um melhor desempenho dos idosos em suas atividades, favorecendo a gestão da própria vida (BARKER; JONES; JENNISON, 1995).

Em relação às oficinas de atividades manuais (Figura 3), foram formadas cinco oficinas (duas no primeiro semestre e três no segundo semestre), com uma média de dez inscritos por oficina, totalizando 46 inscritos.

As atividades manuais da oficina foram realizadas com a participaçáo efetiva dos idosos, que se envolveram desde a organização dos materiais até o ensino de técnicas, utilizando a capacidade criativa e expressiva na confecção de objetos, que foram elaborados com diversas finalidades ao longo do
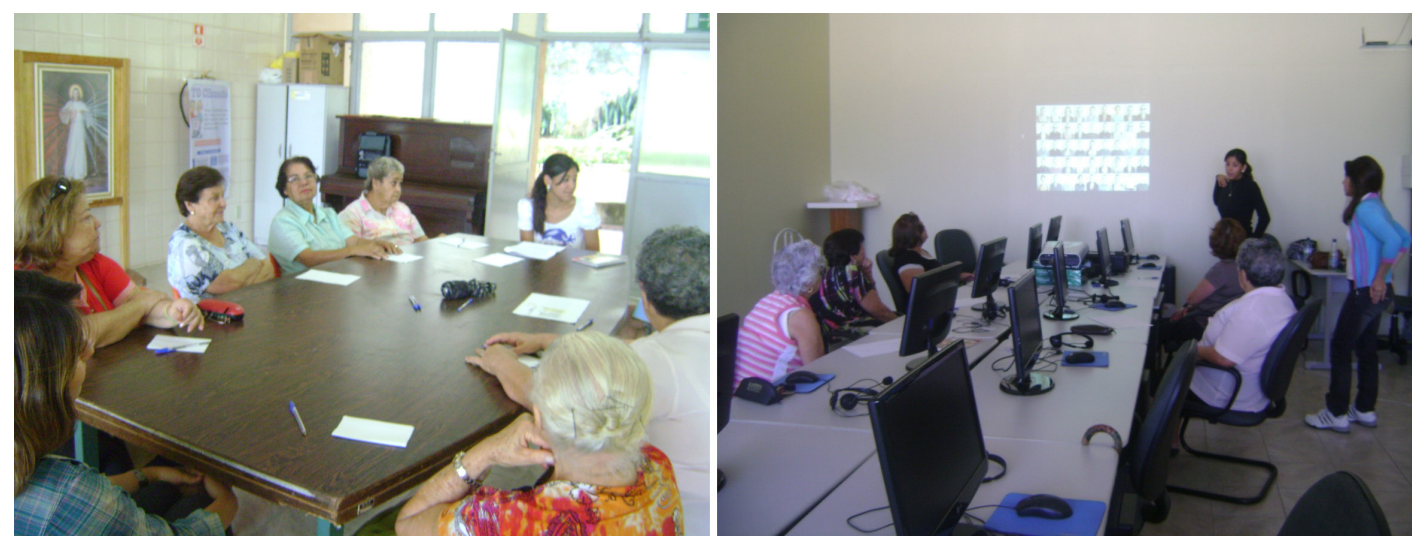

Figura 2. Momentos da oficina de Estimulação Cognitiva. 
período de cada grupo. Segundo Martinelli (2011, p. 112), cada profissional apresenta uma forma de atuar e uma compreensão da ocupaçáo humana; desta forma, existe

[...] a necessidade de compreender a atividade de uma forma mais ampla no sentido de identificar com os próprios interessados suas ações e as representaçôes que elas têm em suas vidas.

A reflexão realizada pelo grupo possibilitou que os idosos construíssem um espaço de trocas sustentado pelo terapeuta ocupacional, dando sentido ao seu fazer.

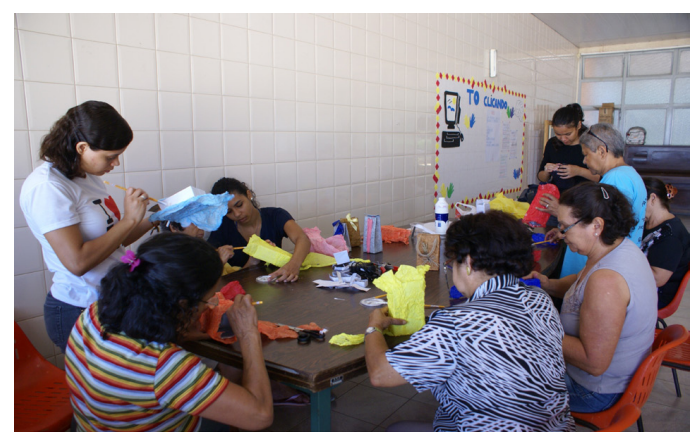

Figura 3. Oficina de atividades manuais.
No mês de junho, foi realizada uma festa junina para confraternização e comemoração do fim das oficinas oferecidas no primeiro semestre (Figura 4), além de promover a inclusão social dos participantes. No mês de dezembro, uma confraternização natalina foi realizada com os mesmos objetivos.

Essas atividades se caracterizam por exigirem escolha pessoal, sendo um momento em que o idoso pode exercer sua autonomia e "adquirir uma grande oportunidade de realização pessoal, direcionando um viver mais feliz" (MARTINELLI, 2011, p. 114). As atividades proporcionadas pelo projeto exploraram as capacidades dos sujeitos e foram utilizadas como instrumento de inclusão social, sendo o papel dos extensionistas o de provocar o estímulo e favorecer o resgate da autonomia.

O grande número de pessoas inscritas demonstra que as atividades oferecidas atendem ao interesse dessa faixa etária e trazem novas perspectivas de inserção e ampliação da participação social, bem como de melhoria das condições de saúde e qualidade de vida dos idosos.

De acordo com Terra (2008), uma velhice ativa deve ser acompanhada de oportunidades contínuas de participação, permitindo aos idosos perceberem
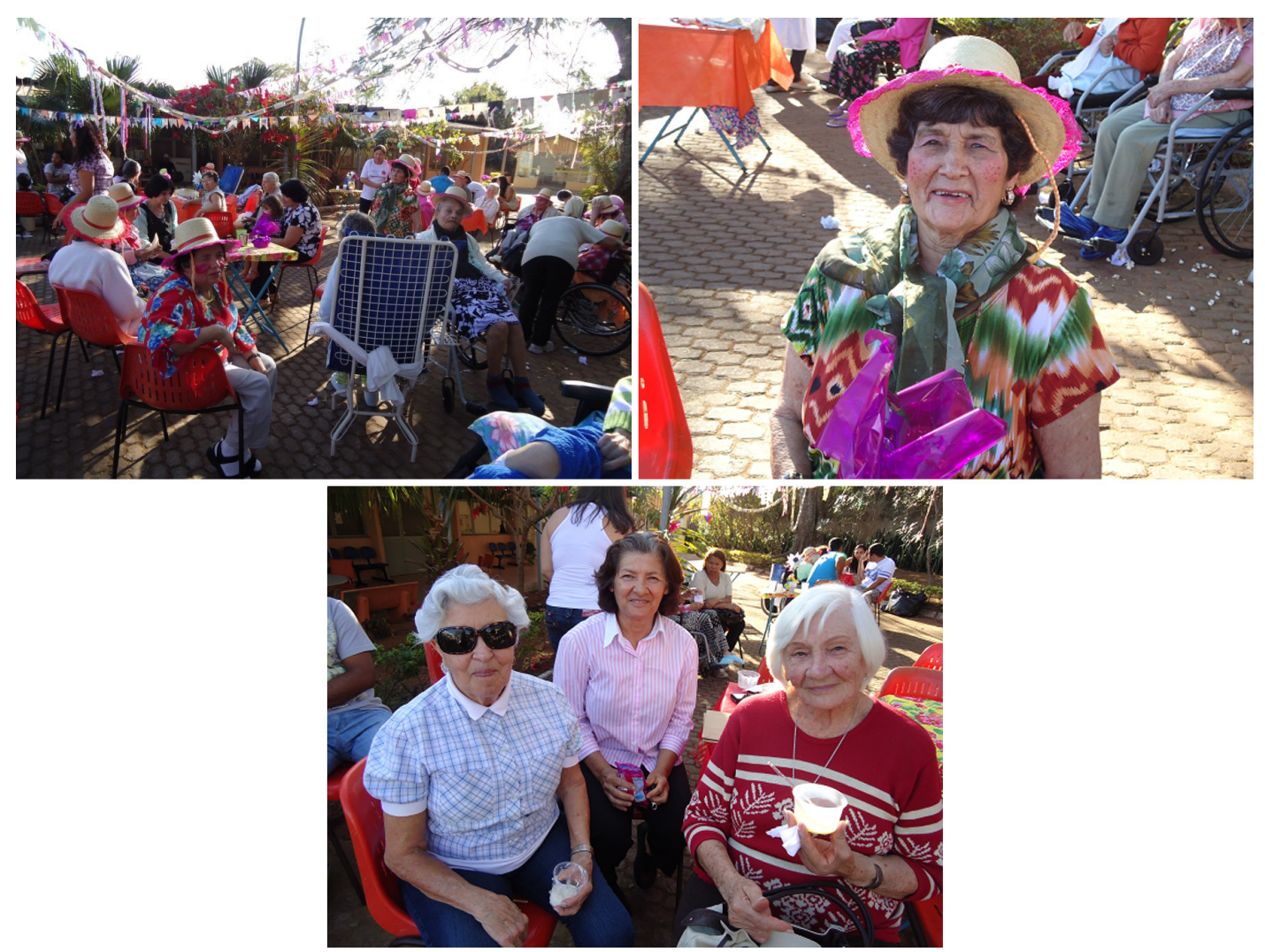

Figura 4. Festa Junina. 


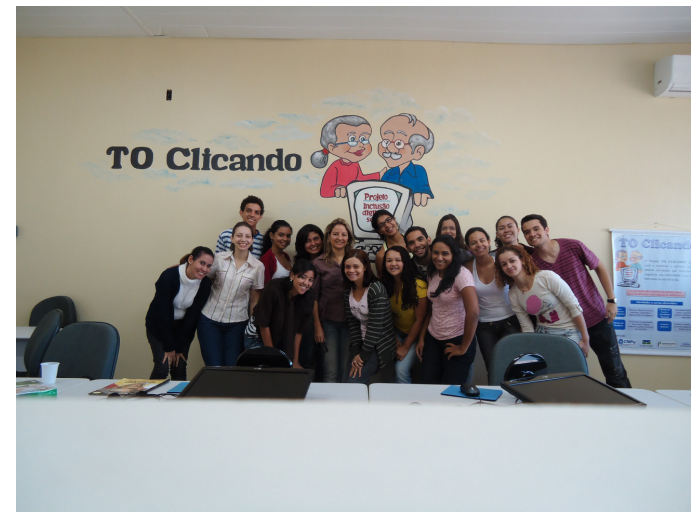

Figura 5. Parte da equipe do Projeto "TO Clicando" em 2011.

todo o seu potencial ao longo da vida e serem socialmente participantes, de acordo com suas capacidades, necessidades e vontades.

A visão preconceituosa sobre o envelhecimento, comum em nossa sociedade, muitas vezes decorre da insuficiente informação a respeito do processo, gerando significados e imagens negativas, e comprometendo a vivência e a interação entre as pessoas. Esses significados compóem estereótipos que podem ou náo levar à exclusão ou à valorização dos idosos na comunidade (GUERRA; CALDAS, 2010).

Neste contexto, o projeto favoreceu o contato de jovens e idosos, além de possibilitar ao idoso a percepção de sua capacidade de aprender novas habilidades e adquirir novos conhecimentos, indo contra os estigmas e preconceitos da sociedade para com esta faixa etária.

Além das contribuições comunitárias, o Projeto possibilitou contribuiçôes acadêmicas por meio da participação de alunos e professores da UnB, abrindo campo para pesquisa, estágio, práticas e outras atividades. A equipe técnica do Projeto TO Clicando em 2011 (Figura 5) foi composta por um coordenador, quatro professores colaboradores, sete alunos extensionistas com bolsa $\mathrm{CNPq}$, dois alunos extensionistas com bolsas do Programa Institucional de Bolsas de Extensão - Pibex/UnB, sete alunos com bolsa permanência - UnB e três alunos extensionistas voluntários. O projeto TO CLICANDO possibilitou o desenvolvimento do projeto de pesquisa intitulado "Impacto de Oficinas de Memória, Informática, Lazer e Atividades Manuais na Qualidade de Vida e no Desempenho Funcional e Cognitivo de Idosos Institucionalizados e Comunitários", com a participação de dois alunos de Iniciaçâo Científica e apresentação de nove trabalhos em congressos científicos, sendo quatro no Congresso Centro-Oeste de Geriatria e Gerontologia (2011) e cinco no XII Congresso Brasileiro e IX Congresso Latino-Americano de Terapia Ocupacional (2011).

A partir de 2011, sem o financiamento do Edital MCT/CNPq n.o 49/2010 - REID/Casa Brasil, o projeto TO Clicando continuou em funcionamento, mantendo as demais parcerias, e vem se aperfeiçoando desde então. Outras atividades foram oferecidas, como curso de fotografia e de dança sênior. Essas atividades são oferecidas de acordo com o interesse dos idosos, com a capacidade técnica dos monitores e com os recursos financeiros disponíveis.

\section{Conclusão}

O Projeto TO Clicando tem se tornado um espaço de aprendizagem, socializaçáo e inclusão social e digital do idoso. O Projeto tem permitido uma importante articulação entre ensino, pesquisa e extensão universitária, ao contar com a participação de docentes, discentes bolsistas e voluntários. Tem desenvolvido uma rede de cooperação que envolve o compromisso institucional da $\mathrm{UnB}$, previsto em seu Plano de Desenvolvimento Institucional (PDI) e sua missão de produzir, integrar e divulgar conhecimento, formando cidadáos comprometidos com a ética, a responsabilidade social e o desenvolvimento sustentável. Além disso, abre a possibilidade de abertura de novos campos de práticas e de estágio para as disciplinas do curso de graduação em terapia ocupacional e de outros cursos da UnB, além de fomentar a produção científica na área.

\section{Agradecimentos}

Ao Conselho Nacional de Desenvolvimento Científico e Tecnológico - CNPq, ao Programa Providência de Elevação da Renda Familiar e ao Lar dos Velhinhos da Associação São Vicente de Paulo (Taguatinga, DF).

\section{Referências}

BARKER, A.; JONES, R.; JENNISON, C. A. Prevalence study of age-associated memory impairment. The British journal of psychiatry, London, v. 167, n. 5, p. 642648, 1995.

DIAS, E. G.; DUARTE, Y. A. O.; LEBRÃO, M. L. Efeitos longitudinais das atividades avançadas de vida diária em idosos: implicações para a reabilitação gerontológica. O Mundo da Saúde, São Paulo, v. 34, n. 2, p. 258-267, 2010.

FELICIANO, A. B.; MORAES, S. A.; FREITAS, I. C. M. O perfil do idoso de baixa renda no Município de São Carlos, São Paulo, Brasil: um estudo epidemiológi- 
co. Cadernos de Saúde Pública, Rio de Janeiro, v. 20, n. 6, p. 1575-1585, 2004.

FERREIRA, A. J. et al. Inclusão Digital de Idosos: a descoberta de um mundo novo. Porto Alegre: EDIPUCRS, 2008 .

GOLDFARB, D. C.; LOPES, R. G. C. Avosidade: a família e a transição psíquica entre as geraçóes. In: FREITAS, E. V. et al. Tratado de geriatria e gerontologia. Rio de Janeiro: Guanabara Koogan, 2006. p. 1374-1382.

GUERRA, A. C. L. C.; CALDAS, C. P. Dificuldades e recompensas no processo de envelhecimento: a percepção do sujeito idoso. Ciência e Saúde Coletiva, Rio de Janeiro, v. 15, n. 6, p. 2931-2940, 2010.

GURIAN, M. B. F. Rastreamento cognitivo por instrumento baseado no MEEM em idosos não institucionalizados residentes em Batatais - SP. 2002. 87 f. Dissertação (Mestrado em Saúde na Comunidade) - Universidade de São Paulo, Ribeirão Preto, 2002.

HSU, H. C. Does social participation by the elderly reduce mortality and cognitive impairment? Aging Ment Health, Abgidon, v. 11, n. 6, p. 699-707, 2007.

INSTITUTO BRASILEIRO DE GEOGRAFIA E ESTATÍSTICA - IBGE. Censo 2010. Rio de Janeiro, 2010. Disponível em: <http://www.ibge.gov.br/home/ estatistica/populacao/projecao_da_populacao/2013/default_tab.shtm>. Acesso em: 26 nov. 2014.

LIMA-COSTA, M. F; BARRETO, S. M.; GIATTI, L. Condiçóes de saúde, capacidade funcional, uso de serviços de saúde e gastos com medicamentos da populaçáo idosa brasileira: um estudo descritivo baseado na pesquisa Nacional por Amostra de Domicílios. Cadernos de Saúde Pública, Rio de Janeiro, v. 19, n. 3, p. 735-743, 2003.
MARTINELLI, A. S. A importância de atividades de lazer na Terapia Ocupacional. Cadernos de Terapia Ocupacional da UFSCar, São Carlos, v. 19, n. 1, p. 111-118, 2011.

NUNES, V. P. C. A inclusão digital e sua contribuição no cotidiano de idosos: possibilidade para uma concepção multidimensional de envelhecimento. 2006. $53 \mathrm{f}$. Dissertação (Mestrado em Gerontologia Biomédica) Pontifícia Universidade Católica do Rio Grande do Sul, Porto Alegre, 2006.

OliveIRA, A. M.; GARCIA, P. A. Perfil demográfico, clínico e funcional de idosas participantes e não-participantes de atividades comunitárias ligadas à igreja. Revista de Terapia Ocupacional da Universidade de São Paulo, São Paulo, v. 22, n. 2, p.153-161, 2011.

RAYMUNDO, T. M. Aceitação de tecnologias por idosos. 2013. 78 f. Dissertação (Mestrado em Ciências) - Universidade de São Paulo, São Carlos, 2013.

SANTOS, P. L.; FORONI, P. M.; CHAVES, M. C. F. Atividades físicas e de lazer e seu impacto sobre a cognição no envelhecimento. Medicina, Ribeirão Preto, v. 42, n. 1, p. 54-60, 2009.

TERRA, N. L. Prefácio. In: FERREIRA, J. A. et al. Inclusão digital de idosos: a descoberta de um novo mundo. Porto Alegre: EDIPUCRS, 2008. p. 12.

VECHIATO, F. L.; VIDOTTI, S. A. B. G. Contribuiçóes de elementos do construtivismo e da mediação da informação para a inclusão digital de idosos. Informação \& Informação, Londrina, v. 15, n. 2, p. 40-59, 2010.

VERAS, R. Envelhecimento populacional contemporâneo: demandas, desafios e inovaçóes. Revista de Saúde Pública, São Paulo, v. 43, n. 3, p. 548-554, 2009.

\section{Contribuição dos Autores}

Kátia Vanessa Pinto de Meneses foi responsável pela concepção e elaboração, revisão e redação final do texto. Patrícia Azevedo Garcia, Grasielle Tavares Paulin e Carolina Becker Bueno Abreu foram responsáveis pela revisão e redação final do texto. Todas as autoras aprovaram a versão final do texto.

\section{Fonte de Financiamento}

Edital MCT/CNPq n. 49/2010 - REID/Casa Brasil. 